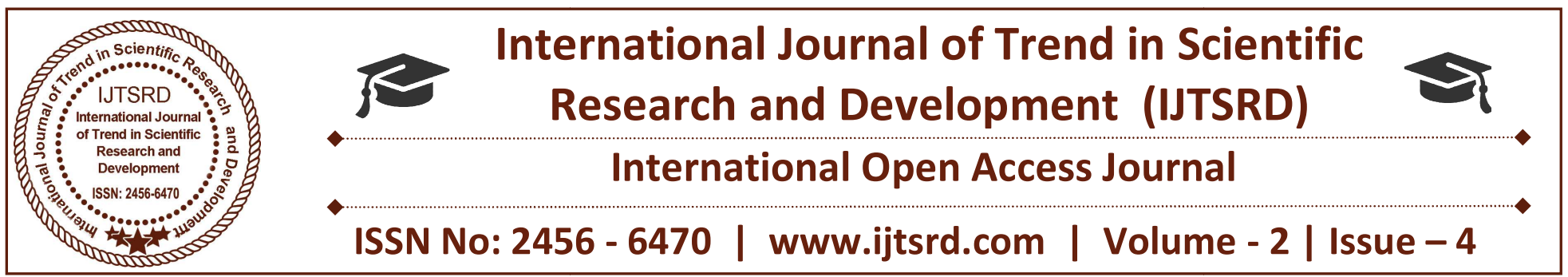

\title{
A Review on "CFD Analysis of Heat Transfer Enhancement of Shell and Tube Heat Exchanger Creating Triangular Fins on The Tube"
}

\author{
Sudhanshu Pathak ${ }^{1}$, S. K. Bharti ${ }^{2}$ \\ ${ }^{\mathbf{1}}$ Research Scholar, Millennium Institute of Technology, Bhopal, India \\ ${ }^{2}$ Assistant Professor, Millennium Institute of Technology, Bhopal, India
}

\section{ABSTRACT}

For evaluation of shell and tube Heat exchanger, thermal performance and pressure drop are dependent on the path of fluid flow and different orientations respectively. Increasing the complexity of fluid flow enhances heat transfer. This paper presents a review on the FEA simulations carried out on shell and tube type Heat exchanger with creating the extended surfaces on the tube wall. From the literature we found that heat transfer enhancement, is done by introduction of extended surfaces in tube side.

Keywords: Shell-and-tube heat exchanger, Heat transfer enhancement, icem CFD, CFD fluent and AL2O3 water nanofluid, pressure drop, heat transfer coefficient.

\section{INTRODUCTION:}

A heat exchanger is a device used to transfer heat between a solid object and a fluid, or between two or more fluids. The fluids may be separated by a solid wall to prevent mixing or they may be in direct contact. There are three primary classifications of heat exchangers according to their flow arrangement. In parallel-flow heat exchangers, the two fluids enter the exchanger at the same end, and travel in parallel to one another to the other side. In counter-flow heat exchangers the fluids enter the exchanger from opposite ends. The counter current design is the most efficient. In a cross-flow heat exchanger, the fluids travel roughly perpendicular to one another through the exchanger. For efficiency, heat exchangers are designed to maximize the surface area of the wall between the two fluids, while minimizing resistance to fluid flow through the exchanger. The exchanger's performance can also be affected by the addition of fins or corrugations in one or both directions, which increase surface area and may channel fluid flow or induce turbulence.

Shell and tube heat exchanger: Shell and tube heat exchangers consist of series of tubes. One set of these tubes contains the fluid that must be either heated or cooled. The second fluid runs over the tubes that are being heated or cooled so that it can either provide the heat or absorb the heat required. A set of tubes is called the tube bundle and can be made up of several types of tubes: plain, longitudinally finned, etc. Shell and tube heat exchangers are typically used for highpressure applications (with pressures greater than 30 bar and temperatures greater than $260{ }^{\circ} \mathrm{C}$ ). This is because the shell and tube heat exchangers are robust due to their shape.Several thermal design features must be considered when designing the tubes in the shell and tube heat exchangers: There can be many variations on the shell and tube design. Typically, the ends of each tube are connected to plenums (sometimes called water boxes) through holes in tubesheets. The tubes may be straight or bent in the shape of a U, called U-tubes.

Literature Survey: In this work Shell and tube Heat exchanger is used to estimate the heat transfer rate. There is a lot of research going on in this area, a few of them are stated below,

Argonne National Laboratory of USA by Choi (1995) which showed that thermal performance of conventional liquid could be remarkably improved using nanoparticles. Nano fluids can be used for a 
wide variety of engineering applications like transportation, electronics, medical, food, defence, nuclear, space, and manufacturing of many types.

J. Koo et al.(2000): Investigated the nanoparticle collision and deposition in the surface wall with help of micro channel heat sink. Which has the dimension of $1 \mathrm{cmx} 100$ micometerx 300 micrometer, water-CuO and Cuo-ethylin glycol Nano fluids are through the micro channel heat sink? They are investigated the base fluid should possess high prandtl number, and get enhanced heat transfer rate by minimize particleparticle and particle-wall collision. Viscous dissipation effect is important of narrow channel, because Nusselt number high for high aspect ratio channel.

Shuichi Torri et al.(2001): Investigated convective heat transfer co efficient of diamond based Nano fluid by using heat tube apparatus. Specification of tube is $4.3 \mathrm{~mm}, 4 \mathrm{~mm}$ outer and inner diameter respectively, and applied 100W power unofomly. They are showed the heat transfer coefficient is increases with increasing concentration and Reynolds number of Nano fluid. But at the same time increased the pressure drop with increasing concentration of Nano particle.

PaisarnNaphon et al.(2003): Investigated the thermal efficiency of heat pipe using titanium-alcohol Nano fluid, heat pipe dimensions are $60 \mathrm{~mm}$ and $15 \mathrm{~mm}$ length and outer diameter respectively. The thermal efficiency increases with increasing tilt angle within $60^{\circ}$ angle and concentration of nanoparticle.

Anil Kumar et al.(2004): studied the heat transfer enhancement of fin, utilizing $\mathrm{AL}_{2} \mathrm{O}_{3}$-Water Nano fluid analyzed using CFD. Rayleigh number increases due to Brownian motion, ballistic phonon transport, clustering and dispersion effect of nanoparticle. At high Rayleigh number flow rate at center of the circulation is increasing, so temperature is drop from center of fin. Volume of the circulation increases the velocity at center is increases as the result of increasing the solid-fluid heat transportation. Low aspect ratio fin is suitable for heat transfer enhancement, because heat affected zone is less.

Yu-Tang chen et al.(2005): Investigated the thermal resistance of heat pipe using Ag-DI Water Nano fluid, heat pipe made as $200 \mathrm{~cm} \times 3 \mathrm{~mm}$ length and thickness respectively. Heat resistance is increases with increasing concentration of Nano fluid up to $50 \mathrm{ppm}$.
Due to wettability of nanoparticle various geometry of wick is created on heat pipe.

Eed Abdel Hafez Abdel-hadi et al.(2006): Investigated the heat transfer analysis of vapor compression system using CuO-R134a Nano fluid, test section made of copper horizontal tube and heat is applied 10-40 KW/m². Heat flux, concentration, and size particle is important factor to enhance the heat transfer rate of Nano fluid. Heat transfer rate is increases with increasing heat flux, up to $55 \%$ of concentration of Nano fluid and up to $25 \mathrm{~nm}$ sized particles.

Somchaiwongwises et al.(2007): Investigated heat transfer enhancement and flow characteristic of $\mathrm{Al}_{2} \mathrm{O}_{3}$-Water Nano fluid using micro channel heat sink. The dimension of test section is $5 \times 5 \mathrm{~mm}$ and $50 \mathrm{~W}$ heat is applied. Heat transfer is enhanced at high Reynolds number and high concentration of Nanofluid, because at high Reynolds number wall temperature is decreases and pressure drop is increased.

\section{CONCLUSION:}

For efficiency, heat exchangers are designed to maximize the surface area of the wall between the two fluids, while minimizing resistance to fluid flow through the exchanger. The exchanger's performance will be affected by the addition of fins which increase surface area and induce turbulence.In this work the CFD simulation of shell and tube heat exchanger have been done on Ansys 14.5. Meshing of the model will be done in the icem CFD and the numerical simulations have been done in the CFD post processing Numerical validation also be done.

\section{REFERENCES}

1. U.C. Kapale, S. Chand, Modelling for shell-side pressure drop for liquid flow in shell-and tube heat exchanger, International Journal of Heat and Mass Transfer 49 (2006) 601-610.

2. M. Reppich, J. Kohoutek, Optimal design of shelland-tube heat exchangers, Computers and Chemical Engineering 18 (Suppl. 1) (1994) S295S299.

3. J.R. Thome, Heat transfer augmentation of shelland-tube heat exchangers for the chemical processing industry, Journal of Enhanced Heat Transfer 4 (2) (1997) 147-161. 
4. R. Hosseini, A. Hosseini-Ghaffar, M. Soltani, Experimental determination ofshell side heat transfer coefficient and pressure drop for an oil cooler shell and-tube heat exchanger with three different tube bundles, Applied Thermal Engineering 27 (2007) 1001-1008.

5. H. Li, V. Kottke, Analysis of local shell-side heat and mass transfer in the shelland- tube heat exchanger with disc-and-doughnut baffles, International Journal of Heat and Mass Transfer 42 (1999) 3509-3521.

6. J. Taborek, Shell and Tube Heat Exchangers: Single Phase Flow, in HeatExchanger Design Handbook, Section 3.3, Hemisphere, New York, 1982.

7. R. Mukherjee, Effectively design shell-and-tube heat exchangers, ChemicalEngineering Progress 94 (2) (1998) 21-37.

8. M. Saffar-Avval, E. Damangir, A general correlation for determining optimumbaffle spacing for all types of shell and tube exchangers, International Journal of Heat and Mass Transfer 38 (13) (1995) 2501-2506.

9. D. Eryener, Thermoeconomic optimization of baffle spacing for shell and tubeheat exchangers, Energy Conversion and Management 47 (2006) 1478-1489.

10. W. Roetzel, D. Lee, Experimental investigation of leakage in shell-and-tubeheat exchangers with segmental baffles, International Journal of Heat and Mass Transfer 36 (15) (1993) 3765-3771.

11. W.Roetzel,D.W.Lee, Effect ofbaffle/shell leakage flow on heat transfer in shell-andtubeheat exchangers, Experimental Thermal and Fluid Science 8 (1994) 10-20.

12. H.D. Li, V. Kottke, Effect of the leakage on pressure drop and local heat transferin shell-andtube heat exchangers for staggered tube arrangement, International Journal of Heat and Mass Transfer 41 (2) (1998) 425-433.

13. M.Y. Xiao, Experimental Error Computation and Data Processing, ScientificPress, Beijing, China, 1981.

14. D.Z. Xu, Thermal Technical Measurement and Experimental Data Processing,Shanghai Jiaotong University Press, Shanghai, China, 1991.
15. R.K. Shah, S. Kakac, A.E. Bergles, Compact Heat Exchanger Design Procedures.Thermal-Hydraulic Fundamentals and Design, Hemisphere/MC Graw-Hill,Washington DC, 1981.

16. S.M. Yang, W.Q. Tao, Heat Transfer, second ed., Advanced Educational Press,Beijing, 1998. 